\title{
ALGUMAS AÇÕES PARA PREVENÇÃO DE SUICÍDIO DESENVOLVIDAS NA UFPE
}

\author{
Rubenilda M ${ }^{\text {a }}$ Rosinha Barbosa - rosinha.barbosa@uol.com.br ${ }^{1}$ \\ Darlindo Ferreira Lima - darlindo.ferreira@gmail.com \\ Davi Barbosa Cavalcanti - davi.barbosa@hotmail.com²
}

\begin{abstract}
Resumo - O suicídio, conforme a Organização Mundial de Saúde (OMS), encontra-se entre as dez primeiras causas de morte nos países industrializados há décadas, afetando a todos que convivem direta ou indiretamente com essa tragédia. Visando contribuir para a sua prevenção, a presente pesquisa-ação, iniciada em março de 2016 e com previsão de término para dezembro de 2020, ancora-se no referencial teórico-metodológico da prevenção ao suicídio, promoção da resiliência, psicologia clínica e comunitária e teoria de redes. Entre os resultados, destacamos ações que facilitaram a sensibilização sobre a problemática, bem como as de intervenção para evitá-la, como os acolhimentos, as oficinas de promoção da resiliência, os plantões, as palestras, os panfletos informativos sobre a prevenção do suicídio, dentre outras. Acreditamos que a discussão aqui realizada poderá contribuir tanto para o aumento do capital social de comunidades envolvidas com a prevenção do suicídio, quanto na formulação, implementação e acompanhamento de políticas públicas a nível local e regional sobre essa questão.
\end{abstract}

Palavras-chave: Prevenção de Suicídio, Resiliência, Psicologia Clinica e Comunitária.

\section{SOME SUICIDE PREVENTION OPTIONS DEVELOPED AT UFPE}

\begin{abstract}
According to the World Health Organization (WHO), suicide has been among the top ten causes of death in industrialized countries for decades, affecting everyone who directly or indirectly lives with this tragedy. Aiming to contribute to its prevention, this action-research, which began in March 2016 and is expected to end in December 2020, is based on the theoretical-methodological framework of suicide prevention, promotion of resilience, clinical and community psychology, and network theory. Among the results, we highlight actions that have facilitated awareness about the problem, as well as those of intervention to avoid it, such as welcome, workshops to promote resilience, shifts, lectures, pamphlets on suicide prevention, among others. We believe that the discussion here can contribute both to increasing the social capital of communities involved in suicide prevention and to the formulation, implementation, and monitoring of public policies at the local and regional levels on this issue. Keywords: Suicide Prevention, Resilience, Clinical and Community Psychology.
\end{abstract}




\section{INTRODUÇÃO}

O suicídio é definido como "o ato deliberado, intencional, de causar a morte a si mesmo", ou (...) "um ato iniciado e executado deliberadamente por uma pessoa que tem a clara noção (ou forte expectativa) de que dele pode resultar a morte, e cujo desfecho fatal é esperado" (OMS, 1998, pg.17). É um fenômeno global, ocorrendo em todo o mundo e em qualquer idade (op. cit).

No que concerne à incidência no mundo, o $1^{\circ}$ Relatório sobre a Prevenção ao Suicídio da OMS, em 2014, chamava a atenção dos governos, uma vez que o suicídio não vinha sendo tratado nem prevenido eficazmente. Segundo esse relatório, mais de 800 mil pessoas morriam por suicídio todos os anos no planeta, estimando-se que ocorria um a cada 40 segundos. Além disso, o mesmo documento apontava que aproximadamente $75 \%$ dos suicídios aconteciam em países de baixa e média renda.

Conforme esse Relatório, os métodos mais usados foram envenenamento, enforcamento e armas de fogo. Em relação a ações mitigadoras, evidências da Austrália, Canadá, Japão, Nova Zelândia, Estados Unidos e vários países europeus revelaram que limitar o acesso a estes meios poderiam ajudar a evitar o suicídio. Outra chave para a redução seria o compromisso dos governos nacionais para a criação e implementação de um plano de ação coordenado. Em 2014, dentre os 160 países pesquisados no relatório da OMS, apenas 28 possuiam estratégias nacionais de prevenção do suicídio. Embora o Brasil buscasse, desde 2006, utilizar estratégias de prevenção, a cada 45 minutos uma pessoa morria por suicídio na época dessa publicação da OMS, em 2014.

Anteriormente as taxas de suicídio da OMS eram mais elevadas em pessoas com 70 anos ou mais. Entretanto, na contemporaneidade, o relatório da OMS, em 2016, apresentou o suicídio como a segunda principal causa de morte no mundo entre os jovens de 15-29 anos. Um fato ainda mais alarmante era a frequência com que ele vinha ocorrendo em crianças, adolescentes e adultos jovens. Em meados de 2017, relatórios do governo divulgados nos EUA apontaram para um crescimento sem precedentes nas tentativas e mortes por suicídio entre crianças e adolescentes norte-americanos, sendo a segunda principal causa de mortes de crianças e jovens em idade escolar (12 a 18 anos). A taxa de suicídios infanto-juvenis, segundo o governo americano, era maior que a soma das mortes por câncer, doenças cardíacas e respiratórias, problemas de nascimento, derrame, pneumonia e febre (JORNAL DA BBC, 2017).

No que concerne ao gênero, geralmente a frequência de mortes por suicídio é maior nos homens do que nas mulheres. Não obstante as mulheres realizarem mais tentativas, os homens utilizam métodos mais eficazes. Nos países mais ricos, três vezes mais homens morrem por suicídio do que as mulheres. Homens com 50 anos ou mais são particularmente vulneráveis. Em países de baixa e média renda, adultos jovens e mulheres idosas têm maiores taxas de suicídio do que os seus homólogos de países de alta renda. Mulheres com mais de 70 anos são duas vezes mais propensas a morrer por suicídio do que as mulheres com idades entre 15-29 anos (OMS, 2014).

Os números supracitados provavelmente seriam ainda maiores caso não houvesse a subnotificação de suicídios. Nesse sentido, na Terceira Oficina sobre Prevenção ao Suicídio, evento organizado no Brasil pela Organização Pan-Americana da Saúde/Organização Mundial da Saúde/Ministério da Saúde brasileiro, a coordenadora da Unidade de Determinantes da Saúde, Doenças Crônicas Não Transmissíveis e Saúde Mental da OPAS/OMS no Brasil, Katia Campos

Barbosa, R.; Lima, D.; Cavalcanti, D. - Algumas ações para a prevenção do suicídio desenvolvidas na UFPE. 
(OPAS/OMS, 05/2018), afirmou que "O suicídio é um grave problema de saúde pública e sua prevenção é uma prioridade para a OPAS/OMS". Ressaltando ainda que o trabalho interinstitucional constitui mais um passo em direção ao cumprimento do plano nacional e dos planos locais de prevenção do suicídio, mencionou:

\footnotetext{
É preciso agir de forma multisetorial para evitar essas mortes. Mas não conseguiremos fazer isso sem informações de qualidade. Há uma significativa subnotificação no mundo. E isso ocorre por dois motivos. Primeiro, pela insuficiente capacidade dos sistemas de registro dos países de baixa e média renda. E, segundo, pelo estigma e criminalização, que levam as pessoas a manterem em segredo seus pensamentos suicidas e as famílias a esconderem quando ele de fato ocorre.
}

Diante desse grave problema que afeta a todos (as) que convivem direta ou indiretamente com essa tragédia, as universidades não podem ficar alheias. Nesse sentido, esse trabalho aborda uma pesquisa-ação em andamento, multiprofissional e interdisciplinar, resultante das reflexões e discussões de estudantes e professores acerca dos frequentes casos de suicídio que aconteceram no prédio do Centro de Filosofia e Ciências Humanas da Universidade Federal de Pernambuco/Brasil (CFCH/UFPE).

Como esse assunto mobilizava vários componentes desta Universidade, com o tempo foram se integrando mais docentes, discentes e técnicos das áreas da saúde, humanas e sociais, bem como de algumas instituições existentes na UFPE e redondezas, como a Pró-Reitoria de Extensão e Cultura - PROEXC/UFPE, o Núcleo de Assistência Estudantil - NASE/UFPE, o Serviço de Psicologia Aplicada - SPA/UFPE e o Centro de Valorização da Vida - CVV.

Dessa maneira, o objetivo dessa pesquisa-ação é (a) promover a resiliência em indivíduos/grupos que se encontravam em situação de vulnerabilidade psicossocial e (b) prevenir o suicídio, informando sobre os fatores protetores e os comportamentos de risco, bem como desenvolvendo ações interventivas para evitar essa conduta. Os locais de atuação são a comunidade da UFPE e arredores, que envolve o campus da Cidade Universitária Recife, escolas e algumas organizações públicas e não governamentais. No final de 2020 essa pesquisa-ação será avaliada e aperfeiçoada para ser reaplicada, uma vez que a meta é que seja de fluxo contínuo para reduzir a incidência de suicídios.

\section{Referencial Teórico - Metodológico}

\section{Considerações sobre a temática do suicídio}

\subsection{Fatores de Risco e Vulnerabilidade}

Como o suicídio é um fenômeno multifatorial há várias nuances que podem levar alguém a fazê-lo. Estudiosos acreditam que o principal fator é o psicológico, coexistindo também um desencadear genético. De forma que existem grupos de pessoas que são mais susceptíveis a sua prática: os grupos de risco e vulnerabilidade. Fazem parte desses aquelas pessoas pertencentes a uma minoria que por motivação diversa tem acesso, participação e/ou oportunidade igualitária dificultada ou vetada a bens e serviços universais disponíveis à população (BASTOS, 2002).

Assim, de acordo com a cartilha "Prevenção do suicídio: um recurso para conselheiros (OMS, 2006)”, os comportamentos suicidas são mais comuns em certas circunstâncias devido 
a diversos fatores culturais, genéticos, psicossociais e ambientais. Tais fatores de risco incluem: a) situação socioeconômica e nível de educação baixos, perda de emprego, estrese social, problemas com o funcionamento da família, relações sociais e sistemas de apoio, traumas (como abuso físico e sexual), perdas pessoais, perturbações mentais tais como depressão, perturbações da personalidade, esquizofrenia, abuso de álcool e de substâncias; e b) sentimentos de baixa autoestima ou de desesperança, questões de orientação sexual (tais como a homossexualidade), comportamentos idiossincráticos (tais como estilo cognitivo e estrutura de personalidade), pouco discernimento, falta de controle da impulsividade, comportamentos autodestrutivos, poucas competências para enfrentar problemas, doença física e dor crónica, exposição ao suicídio de outras pessoas, acesso a meios para conseguir fazer-se mal, acontecimentos destrutivos violentos (tais como guerra ou desastres catastróficos).

O conhecimento desses fatores de risco pode orientar a prevenção bem como a intervenção a essas práticas suicidas, ao ajudar a identificar os indivíduos em maior risco. Assim, a formação de conselheiros para que possam avaliar os riscos é de suprema importância para a redução dos suicídios (op.cit.).

\subsection{Fatores de proteção ao suicídio}

Incluem os 1) apoios da família, de amigos e de outros relacionamentos significativos, 2) crenças religiosas, culturais e étnicas, 3) envolvimento na comunidade e vida social satisfatória, 4) integração social do indivíduo como, por exemplo, através do trabalho e do uso construtivo do tempo de lazer, 5) ter acesso a serviços e cuidados de saúde mental, entre outros (Prevenção do suicídio: um recurso para conselheiros, OMS, 2006).

\subsection{Prevenção ao suicídio}

Aumentar a conscientização e quebrar o tabu sobre o suicídio é uma das chaves para alguns países progredirem na luta contra esse tipo de morte. A redução do acesso aos meios de suicídio também pode reduzir as mortes. Outras medidas eficazes incluem relatórios mais comedidos, isto é, responsáveis, do suicídio na mídia, tais como evitar linguagens que fazem sensacionalismo e a descrição precisa dos métodos utilizados (OMS, 2014).

A identificação e o tratamento precoce dos transtornos por uso de substância mental, nas comunidades e pelos profissionais de saúde, em particular, também é uma forma de preveni-lo. Os cuidados, como acompanhamento de profissionais de saúde por meio do contato regular, inclusive por telefone ou visitas domiciliares às pessoas que tentaram o suicídio, juntamente com a prestação de apoio da comunidade, são essenciais, porque as pessoas que já tentaram o suicídio são as que correm maior risco de buscá-lo novamente (OMS, 2014).

\subsection{Cartilhas}

A elaboração e divulgação delas é uma medida que engloba o desenvolvimento de ações educativas em saúde para formar cidadãos mais esclarecidos. No combate ao suicídio, encontra-se como uma medida preventiva universal, já que visa reduzir a incidência de novos casos a partir da oferta de informação à população em geral. Com a propagação de informações acerca do tema, a distribuição de cartilhas é uma medida importante na prevenção ao suicídio porque se trata de um tema altamente estigmatizado e permeado de tabus. A sua desconstrução se faz 
a partir da informação (CAIS; STEFANELLO, 2015). Dentre as Cartilhas mencionamos:

a) Suicídio: informando para prevenir - Conselho Federal de Medicina (2014), direcionada aos profissionais de saúde;

b) Falando abertamente sobre suicídio - Centro de Valorização da Vida - CVV (2015), é destinada a população em geral promovendo esclarecimento acerca da temática;

c) Prevenção do suicídio: Manual dirigido a profissionais das equipes de saúde mental do Ministério da saúde e Organização Pan-Americana da saúde-Universidade Estadual de Campinas (2006) - ênfase especial nas equipes dos Centros de Atenção Psicossociais (CAPS). Essa iniciativa é parte da Estratégia Nacional de Prevenção do Suicídio, que visa reduzir as taxas de suicídios, as tentativas e os danos associados com os comportamentos suicidas, assim como o impacto traumático do suicídio na família, entre amigos e companheiros (as), nos locais de trabalho, nas escolas e em outras institui.

\subsection{Alguns programas de intervenção preventiva}

A seguir selecionamos alguns programas que têm propostas e ações semelhantes com as que executamos e/ou planejamos. Todas as informações foram retiradas dos Links dessas instituições na WEB. De um modo geral, observamos que nelas existem três aspectos que se complementam para uma atuação preventiva em relação aos comportamentos suicidas. Por um lado, existe o repasse das informações procurando sensibilizar a população sobre a problemática do suicídio e a sua prevenção. Por outro, procura-se fortalecer sujeitos e grupos psicossocialmente vulneráveis tanto a nível individual bem como através do estabelecimento de redes sociais de apoio.

\subsubsection{Ações da Universidade Federal de Santa Catarina (Projeto Rondon, 2006)}

Início no projeto Rondon (2006). Teve o planejamento de ações para prevenir o suicídio entre adolescentes indígenas, entre 12 e 15 anos, em São Gabriel da Cachoeira (AM), cidade impactada pelo Projeto Rondom, em 2006. As estratégias foram centradas na "sensibilização e capacitação de equipes de saúde, professores e pais para melhor identificar fatores e comportamentos de risco da conduta suicida" (ADRIANO; GOULART; MORE, 2006), bem como no "desenvolvimento de habilidades práticas de condutas alternativas para sua prevenção" (id., 2006).

\subsubsection{Universidade Estadual do Rio de Janeiro (UERJ Pela Vida)}

Iniciou em 2010 objetivando a diminuição dos suicídios no campus. Para isso, foi criado o Núcleo de Acolhida ao Estudante (NACE), o qual visou prestar serviços de orientação e assistência preliminar no campo da preservação da saúde mental e físico-emocional dos indivíduos vinculados à UERJ. O NACE estrutura seu atendimento à população em três etapas: acolhimento, encaminhamento e monitoramento. Em meados de 2014, o projeto transformou-se em um programa, dando origem a quatro outros projetos que atenderiam às demandas na Universidade, assim como fortaleceriam e ampliariam as ações que vinham sendo estabelecidas pelo Programa UERJ pela Vida e pelo Núcleo de Acolhida ao Estudante (NACE). (http://www. uerjpelavida.uerj.br/) (SPA/ UERJ). 


\subsubsection{Centro de Valorização da Vida (CVV)}

É uma ONG fundada em 1962 por um grupo de voluntários, em São Paulo. Sua atuação se baseia em fornecer apoio emocional essencialmente pelo trabalho voluntário de milhares de pessoas distribuídas por todas as regiões Revista dos Mestrados ISSN - 2317 - 0115 Profissionais - RMP v. 9, n. 1. (2020) https://periodicos.ufpe.br/revistas/RMP Recife - PE - UFPE / CCSA - MGP RMP 78 Barbosa, R.; Lima, D.; Cavalcanti, D. - Algumas ações para a prevenção do suicídio desenvolvidas na UFPE. do Brasil. Esses voluntários são devidamente treinados para conversar com qualquer pessoa que procure ajuda e apoio emocional, garantindo a todos o respeito, anonimato, não aconselhamento, não julgamento e o estreito sigilo sobre tudo que for dito. $\mathrm{O}$ atendimento está disponível por 24 horas, todos os dias. Pode ser por telefone, chat, e-mail, VoIP, correspondência ou pessoalmente nos postos do CVV em todo o País. Como missão, o CVV preza por valorizar a vida, contribuindo para que as pessoas tenham uma existência mais plena e, consequentemente, prevenindo o suicídio.

\subsubsection{PPS VIDA SIM (Candelária - RS)}

Proposta formulada pela Secretaria Municipal de Saúde e pela Empresa de Assistência Técnica e Extensão Rural (EMATER) da Candelária, Rio Grande do Sul. Objetiva reduzir a incidência de novos casos de suicídio através de ações educativas, em termos seletivos, com grupos expostos à situação de risco, e em termos específicos, quando se dirige a indivíduos que manifestam desejo de ideação suicida. Em relatos de profissionais de saúde do programa, foi visto como o assunto suicídio era encoberto e precisava ser reconhecido e tratado como tal para que houvesse alguma forma de ação e intervenção em relação à repetição de casos. Com o reconhecimento, começou-se a prestar mais atenção no fenômeno, não o tratando como tabu. Observou-se também a necessidade de sempre ocorrer capacitação e sensibilização de modo intersetorial, de forma que envolvesse a todos os profissionais que precisassem lidar de alguma maneira com o fato - o que abrangeria não só os profissionais de saúde, mas também os do Judiciário e os de segurança, como delegados, policiais e bombeiros. Perceberam os autores, no andamento dessa proposta, como foi necessária uma articulação entre redes, bem como o envolvimento das pessoas das comunidades, construindo relações de vínculos de confiança, solidariedade, espírito de equipe, colaboração mútua, como fundamentos para a atenção integral, primária e de linhas de cuidado em saúde. Com isso pode-se pensar a importância dos afetos nas relações entre as pessoas, na formulação de espaços e lugares de abertura e diálogo, desconstrução de relações de poder e dedicação de profissionais envolvidos, que também precisavam se cuidar para poder cuidar as pessoas.

\subsection{Grupos em situação de vulnerabilidade psicossocial}

Listam-se as iniciativas.

\subsubsection{Adolescentes e jovens}

Aqui se encontram-se porque a passagem da adolescência para a vida adulta pode vir a atuar como fator de risco para ideações e tentativas de suicídio. Nessa transição existem vários componentes físicos e psicossociais, tais como a busca de si mesmo e da identidade; a separação progressiva dos pais; a vinculação ao grupo; a evolução da sexualidade; atitude social reivindicatória, variações frequentes do humor e contradições sucessivas, dentre outros (ABASSADE et al., 2009). 


\subsubsection{Comunidade LGBTI}

Diversos estudos vêm demonstrando que as implicações sociais das práticas sexuais pessoais influenciam nas construções de identidade do sujeito, trazendo dificuldades e enfrentamentos de estigmas. No relatório da Secretaria da Força-Tarefa do Governo dos Estados Unidos (GIBSON, 1989) sobre o suicídio juvenil, revelou-se que os jovens gays são de duas a três vezes mais propensos a tentarem o suicídio comparativamente aos jovens heterossexuais, compreendendo o total de 30\% anual de suicídios juvenis (TEIXEIRAFILHO; RONDINE, 2012).

\subsubsection{Suicídio e transtornos mentais}

A associação é de mais de 90\%, tendo maior destaque a depressão (McGIRR et al., 2007). Conforme a OMS (2014), de cada 100 pessoas com depressão, 15 delas decidem colocar fim a própria vida. Dentre os deprimidos, a dependência química, a ansiedade grave, as crises de pânico, a agitação e a insônia aumentam a chance de morte por suicídio. Contudo, cerca de $60 \%$ a $80 \%$ dos casos podem ser tratados com medicação e psicoterapia em um atendimento primário. Sendo assim, identificar os sintomas da depressão - entre eles a falta de ânimo para viver, sensibilidade, emoções à flor da pele e distúrbios no sono - e entender a seriedade da situação são os primeiros passos para ajudar a pessoa depressiva a reverter essa situação. São várias as causas da depressão, e em muitos casos seu aparecimento está associado a fortes impactos vividos, como perdas, lutos, doenças, conflitos nos relacionamentos, dificuldades ou perdas financeiras (LOVISI et al., 2009). Os outros transtornos mentais que aparecem na literatura associados ao suicídio são os transtornos bipolares do humor, abuso de álcool, esquizofrenia e transtornos de personalidade (MELEIRO, 2004). Várias linhas de evidência sugerem que o denominador comum entre a maioria dos sujeitos que comete suicídio é a presença de comportamentos impulsivos e impulsivo-agressivos. De fato, mais da metade dos casos de pessoas que cometem suicídio preenchem critérios diagnósticos de transtornos da personalidade do grupo $\mathrm{B}$, entre eles o transtorno da personalidade limite, também chamado Borderline, que significa "limítrofe". Este é um grave transtorno mental com um padrão característico de instabilidade na regulação do afeto, no controle de impulsos, nos relacionamentos interpessoais e na autoimagem. A taxa de mortalidade devida ao suicídio é alta, atinge $10 \%$ dos pacientes. (MANUAL DIAGNÓSTICO E ESTATÍSTICO DE TRANSTORNO MENTAL DSM-5, 2014; BODEGA, 2015).

\section{Resiliência}

Conceito originário da física, significa a capacidade de um objeto de retornar ao estado anterior quando cessa a força de um impacto sobre ele, ou seja, resiliência significa a capacidade de se recuperar. Esse construto desde meados do século passado vem sendo apropriado pelas ciências da saúde, humanas e sociais, sendo "a capacidade humana para enfrentar, vencer e ser fortalecido ou transformado por experiências de adversidade” (GROTBERG, 2005, p.15).

O estudo da resiliência foca as potencialidades e capacidades humanas, num movimento contrário à psicologia inclinada para a patologia e os fatores de risco. A resiliência não é um traço inato, nem definitivo, mas ela pode ir sendo construída dependendo do entorno e das relações que o sujeito estabelece (MELILO; ESTAMATTI; CUESTAS, 2005). 
O enfoque da resiliência representa uma mudança de paradigma que inclui a passagem do modelo médico tradicional, centrado na fraqueza e na doença, para outra perspectiva, que inclui também a capacidade de enfretamento, o estímulo às potencialidades, a consideração da esperança, como componentes indispensáveis no desenvolvimento das pessoas. Falamos de fatores de risco e de fatores protetores e da passagem do modelo de risco ao modelo do desafio" (ESTAMATTI; MIRTA, 2005, p. 160).

De acordo com Guzzo (2015) alguns importantes eixos teóricos podem ser destacados no estudo da Resiliência, tais como: a Teoria Ecológica do Desenvolvimento de Bronfenbrenner, a Psicologia Cultural de Rogoff e a Psicologia Histórico-Cultural de Vygotsky. Através dessas abordagens entende-se a Resiliência "como um processo de superação da adversidade cotidiana que se instaura por meio da dialética sujeito e sociedade, da tensão risco e proteção e da efetiva ação sobre as condições concretas de desenvolvimento de crianças, adolescentes e família" (p.xiii). De forma que

É um chamamento à psicologia que se compromete profissionalmente com contextos comunitários e educativos, exercício ainda não predominante entre nós, considerando que ainda não há profissionais de psicologia na rede pública, desde a educação infantil até a universidade, e que, mesmo inseridos nas políticas públicas de assistência social, por meio do sistema universal de assistência social (SUAS), não conseguem mudar a realidade na direção de emancipação familiar, coletiva e individual, somente possível pela tomada de consciência das condições objetivas determinadas politicamente, da organização coletiva, da participação social e da superação das relações sociais atuais (GUZZO, 2015, p.xiii).

Acrescentando, Robertson (2019, p. 20-3) comenta que a Terapia Cognitivo comportamental -TCC - é a base da maioria das abordagens de construção da resiliência, que adaptam as técnicas que tiveram êxito no tratamento da ansiedade e da depressão clínica para serem utilizadas no gerenciamento do estresse em geral.

$\mathrm{Na}$ literatura corrente existe tanto um enfoque individual como comunitário da Resiliência. No que concerne ao individual Robertson (2019) resume algumas características que são apontadas para o desenvolvimento da resiliência: Autoestina, autovalorização ou autoaceitação saudáveis e consciência dos pontos fortes e dos recursos pessoais; Autoconfiança; Boa capacidade de resolução de problemas; Habilidades sociais, como assertividade, empatia e de comunicação; Boa "autorregulação emocional", a capacidade de manejar pensamentos, sentimentos e impulsos à ação de forma adequada (p.19).

Em relação à Resiliência comunitária, Ojeda (2005) e Ojeda e Autler (2006) referem dentre os pilares da resiliência comunitária: a) uma auto-estima coletiva que se refere ao sentimento de orgulho e satisfação em relação ao local onde se vive; b) uma identidade cultural que está vinculada à idiossincrasia de um grupo social; c) o humor social, que se refere à capacidade de um grupo de brincar, de fazer piada em relação a uma situação adversa; d) uma gestão governamental que seja transparente e confiável; e) uma espiritualidade que permita ao grupo perceber uma tragédia como sendo uma prova ou desafio, favorecendo a solidariedade e a capacidade das pessoas para mudarem as circunstâncias difíceis.

Complementando Robertson (2019) coloca que o apoio social é uma das fontes de resiliência mencionada com mais frequência, podendo ser o apoio da família, dos amigos ou de algum grupo civil ou religioso. De maneira que " juntar-se a grupos, fazer amigos e melhorar 
a comunicação são estratégias de longo alcance na construção da resiliência” Robertson (2019, p. 18).

Ratificando Ojeda (2005) e Ojeda e Autler (2006) referem que as redes sociais, as relações e o entorno são colocados como fundamentais para o desenvolvimento da resiliência comunitária.

\section{Redes Sociais}

Nesse contexto, defendemos que prestar atenção na estrutura das redes sociais dos indivíduos, estudando como atuar nela, é fundamental para o desenvolvimento da resiliência comunitária. É por isso que etapas da nossa pesquisa-ação - como capacitação da equipe, oficinas, articulação, panfletagem sobre mitos/verdades do suicídio e intervenção envolvendo alunos, pais e professores - foram pensadas a partir da lógica de rede.

Mas o que seria uma rede? Diversos autores contribuíram para a teoria de redes (Assim DEGENNE; FORSÉ, 1994; SCOTT, 2000; THACKER, 2004; WATTS, 2006), mostrando algumas características como complexidade, instabilidade e elasticibilidade. Em suma, uma rede pode ser interpretada como uma metáfora para se observar padrões de interação entre pessoas e sua inserção em círculos sociais, podendo ser vista a partir de laços entre dois indivíduos, "os atores (pessoas, instituições ou grupos; os nós da rede) e as suas conexões (interações ou laços sociais)" (RECUERO, 2009, p. 24).

O que nos interessa aqui é um aspecto específico de redes: o potencial de ação. Afinal, bem planejadas, o que passa pela coordenação de esforços e compromisso numa estratégia coordenada, ações em rede podem alcançar resultados satisfatórios. Ainda mais na era digital, com características como mobilidade, velocidade e convergência de mídias sendo úteis para divulgar informações no Facebook, Twitter, Instagram etc.

Portanto, a resiliência comunitária pode colher bons frutos através de ações em rede, cujo estudo pode contribuir em áreas como a saúde. Christakis (2009), por exemplo, realiza pesquisas dos efeitos de contágio, demonstrando que se "um amigo do seu amigo ganha peso, você também ganha peso", ou "se um amigo do amigo de seu amigo para de fumar, você também para fumar".

Mas como esse contágio acontece? Segundo Christakis, a chave para responder a essa pergunta é compreender os laços entre as pessoas. "Assim como os cérebros podem fazer coisas que um solitário neurônio não pode fazer, as redes sociais podem fazer coisas que uma única pessoa não pode fazer "' (CHRISTAKIS, 2009, p. viii). Nessa linha de pensamento, a rede social poderia ser vista como uma espécie de superorganismo humano, para lá de complexo.

Numa busca para ilustrá-lo, Christakis (2009, p. 17-26) aponta para as cinco regras que regem uma rede. Na regra 1, nós damos formas a nossa rede, os seres humanos podem fazer e refazer as suas redes sociais o tempo todo ${ }^{2}$, atuando em aspectos como a densidade e centrali-

1 Tradução do autor: "Just as brains can do things that no single neuron can do, so can social networks do things that no single person can do"

2 Christakis (2009) pondera, no entanto, que nem sempre as redes formadas são apenas uma questão de escolha do ator. $\mathrm{O}$ ambiente frequentado por ele pode ter bastante relevância, a exemplo de quando se vive em regiões mais favoráveis à amizade.

Barbosa, R.; Lima, D.; Cavalcanti, D. - Algumas ações para a prevenção do suicídio desenvolvidas na UFPE. 
dade da rede ${ }^{3}$. A regra 2, a nossa rede nos molda, mostra que os contatos dos nossos amigos e familiares são relevantes para a situação dentro da rede, podendo reduzir o número de "saltos" para o acesso a outras pessoas ou recursos. Na regra 3, nossos amigos nos afetam, os exemplos de Christakis são os estudantes que, com colegas de quarto estudiosos, tornam-se mais disciplinados, ou os proprietários de casas que, com jardins bem cuidados, influenciam os seus vizinhos a fazerem o mesmo. A regra 4 é os amigos dos amigos dos nossos amigos nos afetam; em resumo, entre os cerca de seis graus de separação que nos ligam a qualquer outra pessoa do planeta (MILGRAN; TRAVERS, 1969), apenas até três nos influenciam.

A regra número 5 é a rede tem uma vida própria. Ao explicá-la, Christakis recorre à teoria dos enxames (swarms ${ }^{4}$ ), perspectiva teórica, também explorada por Watts (2009) e Thacker (2004), que vê o comportamento de um organismo como sendo consequência da intersecção entre indivíduo, grupo e meio ambiente.

Nesse sentido, nessa pesquisa-ação foram organizados espaços, que serão explicitados na metodologia mais adiante, pensando no funcionamento de redes.

\section{Psicologia Clínica e Comunitária}

Estando essas Psicologias focadas na promoção da saúde mental, no diagnóstico, tratamento e prevenção das doenças, visando o bem estar psicossocial de sujeitos, grupos e comunidades, elas perpassam o andamento dessa pesquisa-ação. Tem uma abordagem humanista, que preza pelo cuidado do ser e do seu crescimento psicossocial.

Nesse sentido, nossa proposta é favorecer os processos de fortalecimento e/ou desenvolvimento da Resiliência individual e comunitária mediante o incentivo ao (a) estabelecimento de relações intra e interpessoais mais produtivas e saudáveis, que permitam uma escuta atenta e compreensiva ao que se passa consigo e com o outro, bem como (b) a formação de redes de apoio solidárias dentro da própria comunidade que facilitem que (c) o contexto social seja permeado pela afetividade, aceitação, valorização e o compromisso com a qualidade de vida de todos.

Portanto, "representando a comunidade um meio físico e social de sobrevivência, defesa, proteção e desenvolvimento de seus moradores (GÓIS, 2005, p. 13), proporciona um espaço que favorece o desenvolvimento da resiliência.

Assim, comunidades resilientes seriam aquelas capazes de desenvolver formas efetivas de lidar com os desafios que se apresentam, dentre eles os enfrentamentos aos comportamentos suicidas.

Comumente a Psicologia clínica se refere ao diagnóstico, intervenção e tratamento psicológico. Nesse projeto estamos utilizando o Acolhimento/Escuta empática e o Plantão Psicológico para acolher e/ou intervir junto a indivíduos que estão em situação de vulnerabilidade psicossocial quanto ao risco de suicídio.

3 Densidade e centralidade são dois conceitos chaves na ARS. A densidade faz uma relação entre o número de ligações diretas existentes de um "nó" e o número total de ligações possíveis, descrevendo a coesão. Já a centralidade mostra a posição do individuo na rede, supondo proximidade e intermediação.

$4 \quad$ Estudar enxames é um exercício para se buscar possibilidades e padrões de redes. Predominantemente biológico, o conceito é antigo e suas raízes se encontram na etologia (estudo do comportamento animal), .

Barbosa, R.; Lima, D.; Cavalcanti, D. - Algumas ações para a prevenção do suicídio desenvolvidas na UFPE. 
A entrada no Programa de Promoção da Resiliência e Prevenção ao Suicídio -PRPS - se dá através da Capacitação na Escuta Empática/ Compreensiva que é ancorada na Abordagem Centrada na Pessoa (ACP), do teórico Carl Rogers (1961). O objetivo é promover uma sensibilização e um treinamento para os integrantes do PRPS para os projetos Acolhimento e Cuidar

Rogers (1961) acreditava na potencialidade do indivíduo para crescer psicologicamente caso fossem dadas as condições necessárias. Essa propriedade dos seres humanos ele denomina Tendência Atualizante, que é um dos conceitos centrais da sua teoria. Dessa forma, a compreensão e a aceitação de si, bem como a modificação de comportamentos e posturas inadequadas seria possibilitada caso ocorresse no diálogo psicoterapêutico uma escuta permeada pela Aceitação Incondicional. Esta compreensão empática, seria uma atitude facilitadora para a criação de um clima favorável para o desenvolvimento psíquico, permitindo a autoaceitação, a autoconfiança, a congruência ou um acordo interno.

No que concerne ao Plantão, é uma modalidade da prática psicológica que tem sido realizada, nos últimos anos, em diversas instituições de formação e assistência no âmbito da saúde, sobretudo para questões emergenciais.

Evangelista (2016, p. 204), a partir de Figueiredo (1993), reafirma o psicólogo como o profissional do encontro, ressaltando, porém, a dimensão fenomênica do que encontro pode aqui representar. Ou seja, "a proposta de Figueiredo de que o psicólogo é profissional do encontro indica, a meu ver, o âmbito fenomênico da psicologia, ou, ao menos, aquele que deveria ser: a existência".

Dentre as formas concretas de lidar com o sofrimento do humano na contemporaneidade a psicologia dispõe do Plantão Psicológico como modalidade da prática clínica. Morato (2011) nos define essa modalidade da seguinte forma:

\footnotetext{
"O Plantão Psicológico é uma ação que, originalmente, é clinico-investigativa, pois busca esclarecer, junto àquele que sofre, uma demanda a partir dele mesma, na tentativa de abrir possibilidades para que ele se responsabilize pelo seu próprio cuidado... é trabalho do plantonista relançar no próprio discurso do cliente àquilo que se apresentou a ele como urgência" (p. 19).
}

A primeira frase utilizada por esta autora indica que o Platão Psicológico é uma ação, diferente de tantas outras compreensões teóricas moderna nas quais ajudam a formatar o arsenal de técnicas a serem utilizadas na prática. Será neste contexto que surgem as primeiras construções sobre o conceito de ação clínica tecido por Barreto (2006) ao afirmá-lo como:

\footnotetext{
“[...] ação clínica voltada à atenção e ao cuidado com o sofrimento, condição originalmente humana. Refiro-me como se manifesta a articulação entre conhecimento como saber e como fazer na ação do psicólogo enquanto estudioso e profissional do acontecer humano".(p.59).
}

Esse conceito de ação clínica nos faz, dentre outras coisas, realizar a seguinte reflexão: se faz sentido pensar o fazer do psicólogo como uma ação e modo de estar-no-mundo-com-o-outro em uma relação de afirmação da alteridade intrínseca ao encontro, pode-se pensar também que será, no âmbito da clínica, um fazer-ação que se dá como agir no qual a história do modo de ser se resume e se dispersa ao mesmo tempo, ou seja, pensar a ação clínica como um 
espaço inaugural, cuja criação implica na emergência do novo.

Lima (2012) sinaliza a dimensão desse fazer-ação fundamental à clínica a partir da sua inserção do Plantão Psicológico:

O Plantão Psicológico em nossa experiência compreende uma forma de relação que se dá como acontecência, como um abrigo, um ethos do cuidar que não se propõe a nada mais do que uma experiência de apropriação de nossa condição existencial de constituir sentido e significado às nossas vivências... A acontecência do plantão implica a ênfase na dimensão de experiência, de um saber que nos atravessa tacitamente e não como acontecimento acabado... nos colocamos em uma atitude ética de abertura para que possa se dar uma experiência ou não. (LIMA, 2012, p.183)

Assim, a ação clínica do plantonista pode também ser compreendida como um "não-lugar" que pode oferecer a experiência da esperança no e do devir, ao mesmo tempo que pode ser também um modo de resistência àquilo (mundo) que lhe chega como pronto e acabado, ou seja, como modalidade da prática na qual pode vir a ser possibilitador da emergência de sentidos e significados.

Por outro lado, implica também em ter o Plantão como aquilo que é co-existente à temporalidade do existir enquanto cuidado. Cuidar aqui se dá como entrega por parte do cuidador do seu modo de ser sem possibilidade do querer controlar o encontro com o outro, dá-se, de certa forma, como mistério próprio da condição humana de ser abertura originária para emergência do Ser como vir-a-ser.

\footnotetext{
“A ação clínica não produz nada. Pelo contrário, ela retira. A ação desalojadora dá margem para o inesperado, deixa que a angústia afine a abertura do mundo que é compartilhada. Quando assim encontro alguém, as técnicas de atendimento psicológico e a familiaridade em ser-psicólogo ruem para um não-saber no qual eu e o outro perdemos o chão" (EVANGELISTA, 2016, p.234).
}

Mas como essa "abertura do mundo" nos chega? O plantão se faz fundamentalmente pela escuta e pela visão do que ali se passa como doação e recolhimento, uma caminhada de acompanhar o aparecer/desaparecer do próprio movimento do Ser, naquilo que de alguma forma já é próprio ao humano em suas situações de estar-no-mundo e recusa constante de sentidos de seu próprio estar sendo no mundo.

Lima (2002) sinalizou para a escuta como um fazer que põe em andamento algo, uma apreensão do grito silencioso da angústia existencial na qual todos se encontram imersos e fadados a lidar como condição do humano. Desta forma, a escuta não é técnica ou algo similar que deve ou pode ser empregado para ter acesso a esse ou aquele aspecto dos sujeitos em situação de sofrimento. A escuta remete necessariamente ao modo de estar em aberto para afetações da fala própria que emerge da angústia do existir. Ao passo que a escuta cumpre um de suas dimensões que é o acolhimento, também é como o próprio encontro. Acompanhar o não-dito, o que se encontra nas entrelinhas, a partir do dito como mostração requer sensibilidade de suportar ao que lhe vem ao encontro em suas diversas formas de se mostrar.

\section{Metodologia}


Como mencionado, a pesquisa-ação foi o método escolhido, tendo como objetivo investigar estratégias e ações que, possibilitando o desenvolvimento da resiliência em pessoas e grupos que se encontravam numa situação de vulnerabilidade psicossocial, facilitassem a prevenção de comportamentos suicidas no Campus da UFPE.

O público-alvo e os locais de atuação são a) os professores, estudantes, técnicos e funcionários de todos os centros que compõem a comunidade acadêmica da UFPE do campus da Cidade Universitária; b) as escolas públicas e algumas organizações não governamentais situadas nas proximidades dessa universidade; c) qualquer pessoa que esteja em situação de vulnerabilidade psicossocial que nos procure.

A equipe técnica é constituída atualmente por 5 Professores (3 Psicologia, 1 Filosofia, 1 comunicação social); 5 psicólogos (as); 2 Assistentes Sociais; 30 a 40 estudantes do curso de Psicologia.

Em relação à operacionalização, em princípio a nossa proposta foi pensada para ser de ações contínuas, até ter sido verificado, em sucessivas avaliações, a eficácia da prevenção ao suicídio e o fortalecimento do processo da resiliência nessa comunidade da UFPE e adjacências. Assim, essa pesquisação, apesar de ter sido idealizada desde o século passado, iniciou em 2016 como projeto piloto, sendo fortemente impulsionada pelo último suicídio que ocorreu em 2015 no Centro de Filosofia e Ciências Humanas da UFPE. Pelos resultados obtidos transformou-se de 2017 a 2020 na modalidade Programa de Fluxo Contínuo da PROEXC/UFPE devido a necessidade de incluir outros projetos. Como a maior parte da equipe técnica é constituída por alunos (as) do Curso de Psicologia da UFPE, a partir do quinto período, todos os semestres temos as capacitações e as etapas mencionadas a seguir, algumas delas se superpondo, para serem realizadas por aqueles (as) que se dispõem a integrar a equipe.

\subsection{Preparação da equipe técnica}

- Capacitação para efetuar o Acolhimento, a Escuta Empática/ Compreensiva;

Submissão a oficinas para o desenvolvimento da Resiliência;

Leituras e discussões sobre as temáticas do suicídio e da resiliência;

Reuniões semanais de grupo para supervisão/acompanhamento dos trabalhos;

Capacitação para o Plantão Psicológico de Prevenção ao Suicídio;

Produção de um diário de campo das ações e reflexões desenvolvidas;

Articulação com redes sociais de apoio na comunidade;

Recomenda-se a toda equipe fazer Psicoterapia

\subsection{Atividades desenvolvidas}

Realização de oficinas de promoção da resiliência para indivíduos/grupos em situação 
de vulnerabilidade psicossocial;

$>$ Divulgação de informações para prevenção do suicídio através de palestras, cartilhas, grupos focais, comunicações via web, Facebook, Blogs e outras;

> Organização de eventos com palestras e discussões sobre prevenção do suicídio;

$>$ Panfletagem na UFPE e em locais públicos do centro do Recife para divulgação dos eventos e distribuição de material informativo sobre a prevenção do suicídio, especialmente nas comemorações do setembro amarelo;

$>$ Entrevistas para televisão, rádios e jornais sobre o tema;

$>$ Produção de vídeos para divulgação das ações que desenvolvemos;

$>$ Estabelecimento de parcerias com o a Pró Reitoria de Extensão e Cultura (PROEXC), o Centro de Valorização da Vida (CVV), o Serviço de Psicologia Aplicada (SPA) e o Núcleo de Assistência Estudantil (NASE) da UFPE;

$>$ Acolhimento/escuta aos indivíduos e/ou grupos que necessitem desabafar;

> Plantão Psicológico às pessoas em situação de vulnerabilidade psicossocial e/ou com ideações suicidas;

> Acolhimento a rede de escolas públicas e Organizações não governamentais, repassando informações, promovendo palestras e discussões sobre a temática do suicídio e da sua prevenção;

$>$ Encaminhamento a locais e/ou profissionais de saúde e a redes sociais de apoio;

Palestras e visitas a escolas que apresentam alunos com ideações suicidas;

$>$ Produção de um vídeo sobre as atividades desenvolvidas nesta pesquisa-ação;

Elaboração de relatórios anuais do projeto e eventos que organizamos;

$>$ Apresentações do projeto em colóquios e congressos;

$>$ Elaboração de artigos;

\subsection{Atividades Planejadas}

$>$ Pósvenção ao suicídio;

> Elaboração de Cartilha sobre a prevenção do suicídio;

$>$ Capacitação sobre a Escuta Empática para voluntários nos centros que compõem a UFPE;

$>$ Acolhimento em todos os Centros da UFPE;

$>$ Grupo de estudo na Abordagem Centrada na Pessoa;

> Grupo de estudo na Logoterapia de Viktor Frankl 


\section{Discussão e Resultados}

Os resultados dessa pesquisa-ação, até o momento, parecem indicar que ela tem funcionado como um incentivo ao desenvolvimento de comportamentos resilientes, bem como ao estabelecimento de relações dialógicas mais produtivas e saudáveis, que permitem uma escuta atenta e compreensiva ao que se passa "consigo" e com o outro. Isso parece ter ocorrido com os dois grupos: equipe técnica e os participantes dos projetos. Em relação a estes últimos, tal fato pôde ser observado, durante as atividades realizadas, pelas expressões de bem-estar dos usuários ao terem suas demandas atendidas, bem como pelos inúmeros agradecimentos dirigidos à equipe pela escuta qualificada e livre de julgamentos. Nesse sentido, o Programa provavelmente favoreceu ao público-alvo e às comunidades em que está inserido.

No que concerne à equipe técnica, a realização dessa pesquisa-ação tem possibilitado uma integração teórico-prática dos conhecimentos assimilados em diversas disciplinas do curso de psicologia. Além disso, o tripé ensino-pesquisa-extensão favorece uma integração dos campos de saberes, bem como uma vivência num projeto que visa à coletividade, mais especificamente à saúde pública. Provavelmente todos (as) dessa equipe foram comtemplados (as), tanto pelas aprendizagens resultantes das vivências, quanto pela oportunidade de prestar serviços à comunidade, favorecendo a construção de uma consciência solidária e cidadã.

Nesse sentido, de maneira geral o Programa propiciou à UFPE articular o ensino, a pesquisa e a extensão com uma questão de saúde pública, o suicídio, gerando publicações, comunicações, vídeos e apresentações em congressos.

Em relação à sociedade, acreditamos que pesquisar e desenvolver estratégias e ações de promoção da resiliência com indivíduos, grupos e comunidades que se encontram em situação de vulnerabilidade psicossocial pode ser de grande utilidade pública, pois: 1) agrega esforços e investimentos financeiros, materiais e intelectuais de instituições públicas; 2) os resultados dessa experiência poderão servir de modelo para aplicações em outras áreas do País e mundo; 3) traz benefícios a cidadãos, comunidades, instituições públicas de saúde e sociedade civil organizada, dentre outras instâncias que convivem direta ou indiretamente com essa tragédia, que, como vimos, gera sérios danos sociais, psicológicos e financeiros.

Além disso, a formação de redes sociais de apoio dentro da própria comunidade favoreceu que o contexto social fosse permeado pela afetividade, aceitação, valorização e o compromisso com a qualidade de vida de todos (as).

\section{Considerações Finais}

Pelas colocações da seção anterior se observa a importância de aprofundar o debate interdisciplinar acerca dos temas e ações que incitam/estimulam o desenvolvimento da resiliência individual e comunitária na superação de crises que possam conduzir a comportamentos suicidas.

Entendendo ser o ato suicida um fenômeno polissêmico e multifatorial, o cenário mundial parece refletir a enfermidade que perpassa a nossa sociedade contemporânea, gerando muitas vezes o desencanto, a desesperança e a falta de expectativas, isto é, fatores que podem favorecer que o indivíduo atente contra si mesmo. 
O alcance social de uma proposta de combate ao suicídio pode ser visualizada pelo compromisso com ações transformadoras de âmbito local voltadas para a melhoria da qualidade de vida de segmentos da população que se encontram em situação de vulnerabilidade psicossocial. Dessa maneira, supomos que os benefícios pessoais, sociais, econômicos e culturais dessa pesquisação aqui apresentada estão sendo abrangentes e compensadores de investimento.

\section{Referências Bibliográficas}

ABASSE, M. L. F et al (2009). Análise epidemiológica da morbimortalidade por suicídio entre adolescentes em Minas Gerais, Brasil. Ciênc. saúde coletiva, Rio de Janeiro. V. 14, n. 2, p. 407416, Available from . access on 15 Dec. 2015.

Rogers, Carl (1961). Tornar - Se Pessoa. [S.1.]: Martins Fontes

http://dx.doi.org/10.1590/S1413-81232009000200010.

ADRIANO, J et al (2006). Ações da UFSC no Projeto Rondon 2006: tecendo redes de 'cuidadores' para prevenção do suicídio. Extensio - Revista Eletrônica de Extensão, n. 4. Disponível https:// periodicos.ufsc.br/index.php/extensio/article/view/5563/5067. Acesso em 26/12/2015.

BARRETO, C. L. B. T.; Morato, H. T. P. Ação clínica e os pressupostos fenomenológicos existenciais. Tese de doutorado: Universidade de São Paulo, São Paulo, Brasil, 2006.

BASTOS, R.L. (2002). Patrimônio Arqueológico, Preservação e Representação Sociais:

Uma proposta para o País através da análise da situação do Litoral Sul de Santa Catarina. Programa de Pós-graduação de arqueologia. Museu de Arqueologia e etnologia. Faculdade de Filosofia, letras e Ciências Humanas. Universidade de São Paulo. São Paulo.

BOTEGA, Neury José. Comportamento suicida: epidemiologia. Departamento de Psicologia Médica e Psiquiatria da Faculdade de Ciências Médicas da Universidade Estadual de Campinas, Campinas, SP, Brasil, 2016. Disponível em https://www.scielo.br/pdf/pusp/v25n3/0103-6564pusp-25-03-0231.pdf. Acesso em 18/03/2018

\section{BOLETÍN DE LA ORGANIZACIÓN MUNDIAL DE LA SALUD.}

Prevención del suicídio, OMS, 2016. Disponível em: https:/www.minsalud.gov.co/sites/rid/Lists/ BibliotecaDigital/RIDE/VS/PP/ENT/boletin-conducta-suicida.pdf. Acesso em 16/12/2018.

CAIS, Carlos Filinto da Silva; STEFANELLO, Sabrina. Prevenção do Suicídio Manual dirigido a profissionais das equipes de saúde mental. Disponível em: http://repositorio.unicamp.br/jspui/ bitstream/REPOSIP/309380/1/Cais CarlosFilintodaSilva D.pdf. Acesso em: 16/12/2015

CENTRO DE VALORIAZAÇÃO DA VIDA. Falando abertamente sobre suicidio. Disponível em: www.cvv.org.br Acesso em 16/12/2015 
CHRISTAKIS, Nikolas. Connected: the surprising Power of our social networks and how they shape our lives. New York: Little Brown Co, 2009

CHRISTAKIS, Nikolas. Connected: the surprising Power of our social networks and how they shape our lives. New York: Little Brown Co, 2009

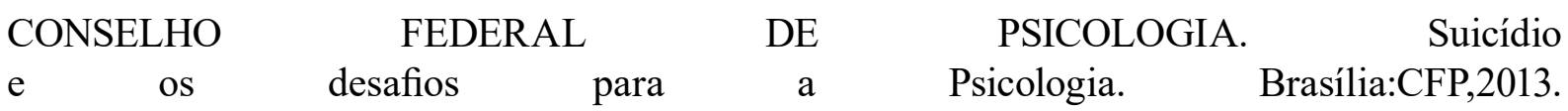

CONTE, M. et al (2012). Programa de Prevenção ao Suicídio: estudo de caso em um município do sul do Brasil. Ciência. saúde coletiva, Rio de Janeiro , v. 17, n. 8, p. 2017-2026, Aug. Disponível em https://www.scielo.br/scielo.php?pid=S1413-81232012000800013\&script=sci abstract\&tlng=pt. Acesso em 24/12/2015

DEGENNE, Alain; FORSÉ, Michel. Introducing Social Networks. London: Sage Publications, 1999.

EVANGELISTA, Paulo Eduardo Rodrigo Alves. Psicologia fenomenológica existencial. A prática psicológica à luz de Heidegger. Curitiba: Juruá, 2016.

FAÇANHA J. D. N. et al (2010). Prevenção do suicídio em adolescentes: programa de intervenção Believe. Revista Eletrônica Saúde Mental Álcool e Drogas, São Paulo, v. 5, n.1 Disponível em http://pepsic.bvsalud.org/scielo.php?script=sci arttext\&pid=S1806-69762010000100002. Acesso em 26/12/2015.

FIGUEIREDO, Luis Cláudio Mendonça. Sob o signo da multiplicidade. in Cadernos de Subjetividade, v.1, 89-95, 1993.

GUZZO, Raquel Souza Lobo (2015). Apresentação: Resiliência um conceito contraditório: a importância do debate. In A Resiliência em Questão: Perspectivas Teóricas, pesquisa e intervenção. COIMBRA, R. M. \& MORAIS, N. A.(Organizadoras). Porto Alegre: Artmed

LIMA, Darlindo. Ferreira de. A prática do plantão psicológico na delegacia especializada de atendimento à mulher (DEAM): uma experiência a partir da acontecência do cuidado. Tese de Doutorado: UFES, 2012.

LIMA, Darlindo. Ferreira de. Compreendendo os sentidos da escuta. Livro Rápido: Olinda, 2002.

LOVISI, Giovanni Marcos et al (2009). Análise epidemiológica do suicídio no Brasil entre 1980 e 2006. Rev. Bras. Psiquiatr., São Paulo , v. 31, supl. 2, p. S86-S93, Oct. Available from . access on 16 Dec. 2015.

Disponível http://dx.doi.org/10.1590/S1516-44462009000600007.

MACHADO, Daiane Borges SANTOS, -Darci Neves dos Suicídio no Brasil, de 2000 a 2012. 
Jornal Brasileiro de Psiquiatria. vol.64 no.1 Rio de Janeiro Jan./Mar. 2015. Disponível em: http:// dx.doi.org/10.1590/0047-2085000000056

MANUAL DIAGNÓSTICO E ESTATÍSTICO DE TRANSTORNO MENTAL DSM-5 / [AMERICAN PSYCHIATNC ASSOCIATION. Porto Alegre: Artmed,2014.

MELILLO, Aldo; OJEDA, Elbio Suárez (org) (2005). Resiliência: descobrindo as próprias fortalezas, Artmed.

MILGRAN, Stanley; TRAVERS, Jeffrey. An Experimental Study of the Small World Problem. Sociometry, vol. 32, no 4, pp. 425-443, 1969. Disponível em: http://snap.stanford.edu/class/ cs224w readings/travers69smallworld.pdf $>$. Acesso em 01.02.2019.

MORATO, Henriette Tognetti Penha. Algumas considerações da Fenomenologia existencial para ação psicológica na prática e na pesquisa em instituições. In $\mathbf{X}$ Simpósio Nacional de Práticas Psicológicas em Instituição - Perspectivas e rumos da Psicologia na atualidade, Niterói- Rio de Janeiro. ANAIS X Simpósio Nacional de Práticas Psicológicas em Instituição - Perspectivas e rumos da Psicologia na atualidade, Niterói - Rio de Janeiro: UFF, v. 1, 24-50, 2011;

OPAS/OMS Brasil - Folha informativa - Suicídio. Organização Pan Americana de Saúde, Organização Mundial de Saúde. 2018.Disponível em https://www.paho.org/bra/index. php?option $=\mathrm{com}$ content $\& v i \mathrm{w}=$ article $\& \mathrm{id}=5671$ :folha-informativa-suicidio $\&$ Itemid $=839$. Acesso em 18/03/2018

PREVENÇÃO DO SUICÍDIO UM RECURSO PARA CONSELHEIROS. Departamento de Saúde Mental e de Abuso de Substâncias Gestão de Perturbações Mentais e de Doenças do Sistema Nervoso Organização Mundial de Saúde - OMS, Genebra 2006. Disponível em https://www.who.int/mental health/media/counsellors portuguese.pdf. Acesso 12/06/2014.

PSIQUIATRIA, Associação Brasileira de. Suicídio: informando para prevenir. (2014). Disponível em: https://www.unimed.coop.br/viver-bem/cartilhas-de-saude/setembro-amarelovamos-prevenir-o-suicidi-1. Acesso em: 16/12/2015

RECUERO, Raquel. Redes sociais na internet. (Coleção Cibercultura). Porto Alegre: Sulina, 2009.

RETS Rede Internacional de Educação de Técnicos em Saúde (2014). Disponível em: http:// www.rets.epsjv.fiocruz.br/noticias/oms, Acesso em: 07/06/2016

ROBERTSON, Donald J. Resiliência: como blindar a sua mente e conquistar a tranquilidade para resolver qualquer adversidade. Porto Alegre: CDG, 2019.

SCOTT, John. Social Network Analysis (Second edition). London: Sage Publications, 2000.

SUÁREZ-OJEDA, E. N. \& AUTLER, L.,(2006) La resiliencia em la comunidad: um enfoque 
social. In: GROTBERG, E. H.(comp.) La resiliencia em el mundo de hoy: cómo superar las adversidades.Gedisa editorial: Barcelona.

THACKER, Eugene. Neworks, Swarms, Multitudes. Part One. Critical Theory, 2004a. Disponível em: <http:/www.ctheory.net/articles.aspx?id=422>. Acesso em 04.02.2019.

. Neworks, Swarms, Multitudes. Part Two. Critical Theory, 2004b. Disponível em: $<$ http:// www.ctheory.net/printer.aspx?id=423>. Acesso em 04.02.2019.

TEIXEIRA-FILHO,F.S.\&RONDINI,C.A.(2012).Ideaçõesetentativasdesuicídioemadolescentes com práticas sexuais hetero e homoeróticas. Saude e Sociedade., São Paulo, v. 21, n. 3, p. 651-667, Sept..Availablefrom.accesson 16Dec.2015.http://dx.doi.org/10.1590/S0104-12902012000300011.

UERJ PELA VIDA. Disponível em: www.uerj pela vida. Acesso em: 16/12/205.

WATTS, Duncan. Seis Graus de Separação (six degrees). A evolução da ciência de redes em uma era conectada. São Paulo: Leopardo Editora, 2009.

WORLD HEALTH ORGANIZATION. Preventing suicide: A global imperative. 2014.

Disponível em https://www.who.int/mental health/suicide-prevention/world report 2014/en/. Acesso em 18/03/2017.

WORLD HEALTH ORGANIZATION. Suicide in the world: Global Health Estimates. 2019. Disponivel em WHO-MSD-MER-19.3-eng\%20(1).pdf. Acesso em 18/03/2019. 